\title{
Tri-isopropylsilyl thioglycosides as masked glycosyl thiol nucleophiles for the synthesis of S-linked glycosides and glyco-conjugates $\uparrow$
}

12, 4816

Received 8th April 2014,

Accepted 8th May 2014

DOI: $10.1039 / \mathrm{c} 4 \mathrm{ob} 00741 \mathrm{~g}$

www.rsc.org/obc

\author{
S. Mandal and U. J. Nilsson*
}

\begin{abstract}
Tri-isopropylsilyl thio-glycosides (TIPS S-glycosides) were synthesized through base promoted $\mathrm{S}_{\mathrm{N}} 2$ substitution of glycosyl halides with TIPS-SH or by Lewis acid promoted glycosylation of TIPS-SH with glycosyl acetates or $p$-methoxyphenyl glycosides. Various thioglycoside derivatives were obtained in high yields by one-pot fluoride-mediated de-silylation and thiol alkylation with alkyl halides or Michael acceptors of one common TIPS S-glycoside.
\end{abstract}

Development of glycomimetics is an important area of research due to their potential as biological tools and in pharmaceutical applications. ${ }^{1,2}$ A large and important class of glycomimetics includes stable analogues in which one or more oxygen atoms, i.e. glycosidic oxygens, have been replaced by e.g. sulfur ${ }^{3,4}$ or other heteroatoms, ${ }^{5}$ leading to structures more tolerable towards enzymatic and acidic hydrolysis and thus with enhanced stability in biological environments. Hence, the enhanced hydrolytic stability of thioglycosides ${ }^{3,4}$ makes them particularly useful as tools in investigation of glycoconjugate functions. Examples include thioglycosides as key mediators for cellular surface recognition and enzyme inhibitors, ${ }^{6}$ and thioglycosides binding to many lectins, ${ }^{7}$ e.g. the unnatural disaccharide thiodigalactoside binding to galectins with about the same affinity as LacNAc. ${ }^{8}$ Indeed, thiodigalactoside shows promising immune-promoting properties against tumor cells ${ }^{9}$ and its derivatives have been shown to attenuate tumor motility, ${ }^{10}$ macrophage differentiation, ${ }^{11}$ fibrosis progression, ${ }^{12}$ hepatitis, ${ }^{13}$ and pancreatic islet cell apoptosis. ${ }^{14}$

Furthermore, thioglycosides are being used as versatile donors and thus key precursors in oligosaccharide synthesis, synthesis of glycodendrimers, ${ }^{15,16}$ sulfur containing glycolipids, ${ }^{4}$ and S-linked protein glycoconjugates. ${ }^{17,18}$ In such a use of thioglycosides, the chemical properties of the thioglyco-

Centre for Analysis and Synthesis, Department of Chemistry, Lund University, POB 124, SE-22100 Lund, Sweden.E-mail: ulf.nilsson@chem.lu.se $\dagger$ Electronic supplementary information (ESI) available: Experimental procedures, characterization data and copies of ${ }^{1} \mathrm{H}$ and ${ }^{13} \mathrm{C}$ NMR of all compounds and COSY and HMQC for selected compounds. See DOI: 10.1039/c4ob00741g side aglycon part typically influence the reactivity and reaction outcome, that is why methods for easy diversification of the thio-glycoside aglycon are of interest. Thioglycoside synthesis is usually performed by $\mathrm{S}_{\mathrm{N}} 2$ displacement of a glycosyl halide by a thiol(ate) or by Lewis acid-catalysed glycosylation of a thiol with glycosyl acetates or phenyl $O$-glycosides. ${ }^{4,5}$ Additional methods include in situ aminolysis and alkylation of thioacetates, ${ }^{19,20}$ Michael type addition of 1-thiolates to carbohydrate enones, ${ }^{21}$ coupling of glycals and thiols in Ferrier-type reactions,${ }^{22}$ thiol-ene click reactions,${ }^{21}$ ring opening of carbohydrate epoxides with thiols, ${ }^{23}$ the use of Lawesson's reagent with hemiacetals, ${ }^{24}$ formation of $\alpha$-thio-glycosidic linkages from 1,6-anhydro derivatives with bis-(trimethylsilyl) sulfide, ${ }^{25}$ formation of $\beta$-thioglycosidic linkages by the use of $\mathrm{Na}_{2} \mathrm{~S}$ and $\mathrm{CS}_{2},{ }^{4}$ and Michael type reactions involving a thiirane intermediate. ${ }^{4}$ In case a collection of thio-glycosides carrying diverse aglycon structures is needed, the majority of these methods would require that a separate (glycosylation) reaction with a thiol was undertaken for each member of the collection. Triisopropylsilyl sulfides are remarkably stable, ${ }^{26}$ yet mildly desilylated and alkylated in the presence of fluoride sources. ${ }^{27-29}$ Triisopropylsilyl thio-glycosides are known and their de-silylation has been demonstrated,$^{30}$ but have not been evaluated as masked glycosyl thiolate nucleophiles for in situ activation and reaction with electrophiles. Herein, we report on a novel, rapid, and effective synthetic method towards different thioglycosides in one step within 5 min by reacting electrophiles with readily accessible tri-isopropylsilyl thio-glycosides as common precursors in the presence of tetrabutylammonium fluoride.

Boron trifluoride etherate-catalysed glycosylation of tri-isopropylsilylthiol (TIPSSH) with anomeric acetates or $p$-methoxy phenyl glycosides, as well as $\mathrm{S}_{\mathrm{N}} 2$ displacement of anomeric bromides with TIPSSH in the presence of a base, $\mathrm{K}_{2} \mathrm{CO}_{3}$, resulted in stereoselective formation of TIPS thio-glycosides (Scheme 1). Evaluation of reaction conditions for the Lewis acid-mediated activation of glycosyl acetates and $p$-methoxyphenyl $\beta$-glycosides revealed that dichloromethane was a solvent superior to toluene, diethyl ether, and acetonitrile for 

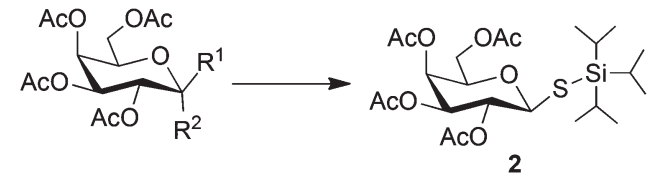

$1 \mathrm{R}^{1}=-\mathrm{OPMP}, \mathrm{R}^{2}=\mathrm{H}$

$3 \mathrm{R}^{1}=\mathrm{H}, \mathrm{R}^{2}=$ OPMP

$4 \mathrm{R}^{1}=\mathrm{OAC}, \mathrm{R}^{2}=\mathrm{H}$

$5 \mathrm{R}^{1}=\mathrm{H}, \mathrm{R}^{2}=\mathrm{Br}$

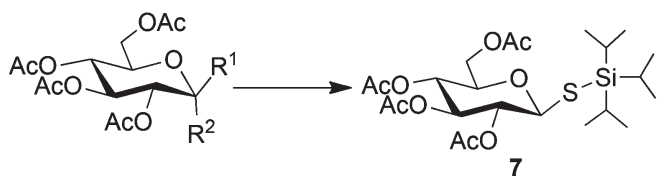

6a $R^{1}=O A c, R^{2}=H$

Method B, 63\% from 6a

6b $\mathrm{R}^{1}=\mathrm{H}, \mathrm{R}^{2}=\mathrm{Br}$
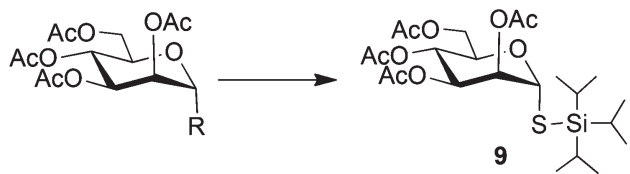

$$
\begin{aligned}
& \mathbf{8 a} R=O A C \\
& \mathbf{8 b} R=B r
\end{aligned}
$$

Method B, 69\% from 8a
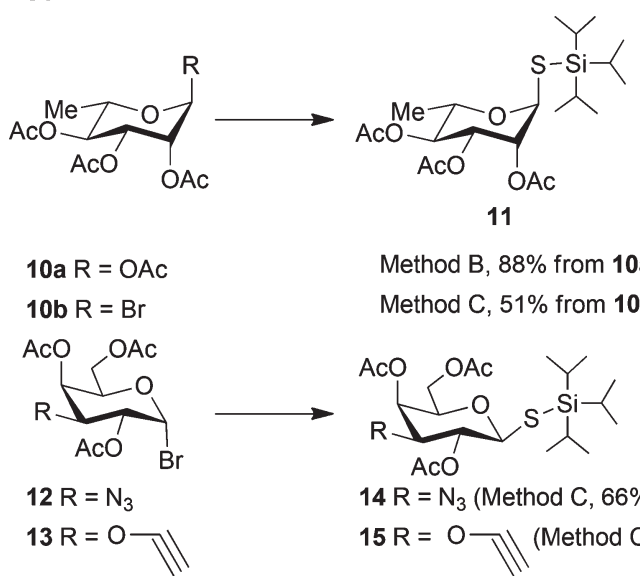

Method B, 88\% from 10a

Method C, $51 \%$ from $10 \mathrm{~b}$

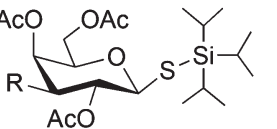

$14 \mathrm{R}=\mathrm{N}_{3}($ Method $\mathrm{C}, 66 \%)$

$15 \mathrm{R}=\mathrm{O} \longrightarrow$ (Method C, 89\%)

Scheme 1 Synthesis of tri-isopropylsilyl thio-glycosides: Method $\mathrm{A}$ : $\mathrm{BF}_{3} \cdot \mathrm{Et}_{2} \mathrm{O}$, TIPSSH, dry toluene. Method $\mathrm{B}: \mathrm{BF}_{3} \cdot \mathrm{Et}_{2} \mathrm{O}, \mathrm{TIPSSH}$, dry DCM. Method C: $\mathrm{K}_{2} \mathrm{CO}_{3}$, TIPSSH, dry acetone.

activation of glycosyl acetates $(\mathbf{4}, \mathbf{6 a}, \mathbf{8 a}, \mathbf{1 0 a})$, while toluene ${ }^{31}$ was the best solvent with $p$-methoxyphenyl $\beta$-galactoside as a donor (1). Furthermore, boron trifluoride etherate proved to be the best choice of Lewis acid over TMSOTf. Among different conditions investigated for the displacement of glycosyl bromides $(\mathbf{5}, \mathbf{6 b}, \mathbf{8 b}, \mathbf{1 0 b}, \mathbf{1 2}, \mathbf{1 3})$ under basic conditions, $\mathrm{NaH}$ in DMF, $\mathrm{Cs}_{2} \mathrm{CO}_{3}$ in DMF, and $\mathrm{K}_{2} \mathrm{CO}_{3}$ in acetone, the best results were obtained with $\mathrm{K}_{2} \mathrm{CO}_{3}$ in acetone. While reasonable yields were obtained by boron trifluoride etherate activation of glycosyl acetates $(\mathbf{4}, \mathbf{6 a}, \mathbf{8 a}, \mathbf{1 0 a})$ and $p$-methoxyphenyl $\beta$-galactoside $\mathbf{1}$, the best yields for formation of TIPS thio-glycosides were obtained using glycosyl bromides $\left(\mathbf{5}, \mathbf{6 b}, \mathbf{1 2},{ }^{32} \mathbf{1 3}{ }^{33}\right)$ in the presence of a base. For mannose and rhamnose the best yields were achieved with Lewis acid-promoted activation of anomeric acetates (8a and 10a).
Cleavage and in situ alkylation of STIPS sulfides have been demonstrated to be efficient with fluoride sources. ${ }^{27}$ Hence, the S-Si bond of the TIPS thioglycosides (2, 7, 9, and 11) was found to be easily transformed into various thioglycosides by activation with fluoride ions in the presence of an electrophile (Michael acceptor, alkyl halide, acid chloride, or glycosyl bromide) in a high-yielding and stereoselective reaction at RT in 5 min on both small and large (gram) scales (Scheme 2). Michael acceptors are known to be highly efficient electrophiles in reaction with thiol(ate) nucleophiles, which proved to also be the case with the conditions for de-silylating and activating TIPS thioglycosides with TBAF (Table 1). Michael additions to methyl propiolate afforded the more stable $E$-isomer exclusively (compounds 17, 18, and 19; Table 1) according to NMR analysis. Hence, the method is of potential value for the construction of hydrolytically stable glycomimetics via thiolate Michael additions.

Neoglycopeptides and proteins are important research tools in glycobiology and S-glycosylated cysteine derivatives are useful building blocks for such structures. Reaction of $\mathrm{N}$-Boc-

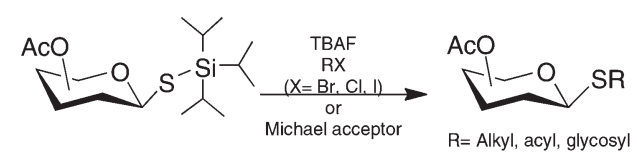

Scheme 2 General scheme for cleavage and in situ alkylation of STIPS glycosides.

Table 1 One-pot de-silylation and glycosyl thiol alkylation with Michael acceptors ${ }^{a}$

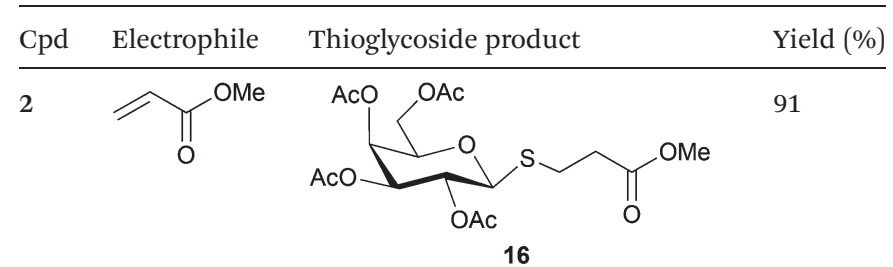

2
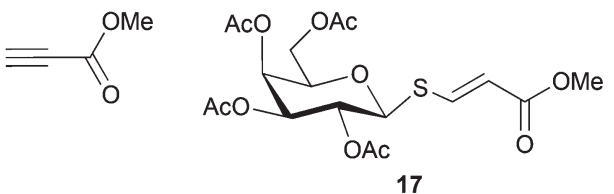

93

7
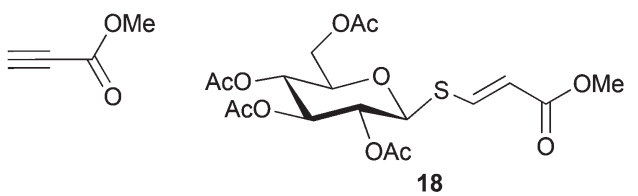

95

9
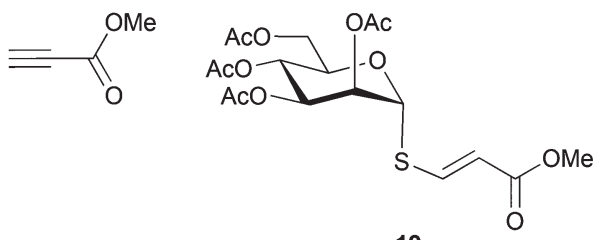

94

${ }^{a}$ STIPS glycoside (1 eq.), Michael acceptor (1.3 eq.), MeCN (26 mL $\mathrm{mmol}^{-1}$ STIPS glycoside), TBAF (1.2 eq., $1.0 \mathrm{M}$ in THF), $5 \mathrm{~min}$. 
protected $\beta$-iodo-L-alanine ester derivatives with TIPS thio-glycosides in the presence of TBAF in acetonitrile at RT for $5 \mathrm{~min}$ furnished the corresponding L-cysteine derivatives 20-24 in excellent yields (Table 2). Hence, the method provides an efficient one step protocol with minimal formation of e.g. eliminated by-products.

To further explore the method, TIPS thio- $\beta$-glycosides were evaluated as masked sulfur nucleophiles with alkyl, acid, and glycosyl halides, including substituted galactosyl bromides $\left(12^{32}\right.$ and $\left.13^{33}\right)$, under the same reaction conditions as described above (Table 3 ). All reactions proceeded smoothly to furnish the corresponding alkyl $\beta$-thioglycosides 25, 27-28, and 30, glycosyl thio-benzoates 26 and 29, and thiodigalactosides 31-33 in excellent yields. In particular, the examples involving synthesis of thiodigalactoside derivatives 31-33 are illustrative of the high efficiency of the STIPS glycosides in the synthesis of thioglycosides as other methods for synthesis of thiodiglycosides including those using glycosyl thiouronium intermediates as masked glycosyl thiolate nucleophiles provide significantly less clean reactions and substantially lower yields in our hands and in published work by others. ${ }^{34-36}$ Further-

Table 2 One-pot de-silylation and glycosyl thiol alkylation with $\beta$-iodo-L-alanine esters ${ }^{a}$

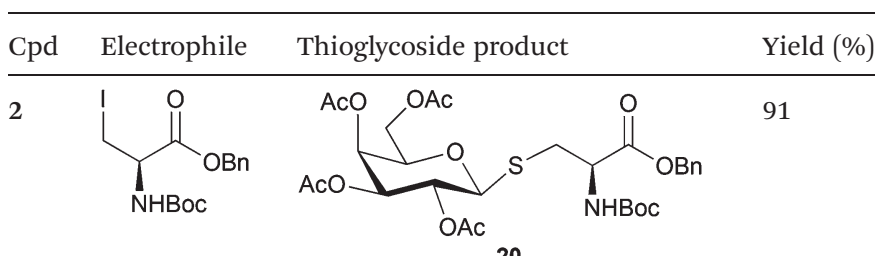

2<smiles>COC(=O)[C@H](N)CI</smiles>

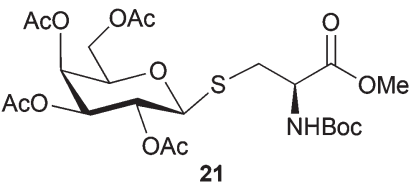

93

7<smiles>COC(=O)[C@H](N)CI</smiles>

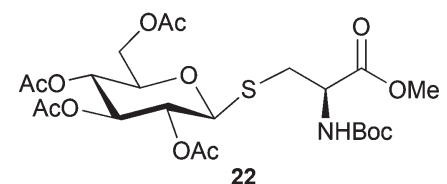

94

9<smiles>N[C@@H](CI)C(=O)OBr</smiles>

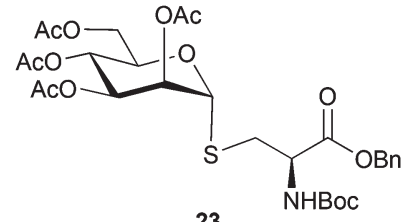

11<smiles>COC(=O)[C@H](N)CI</smiles>

93

94

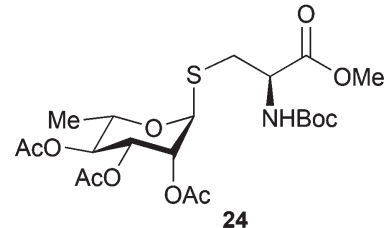

2

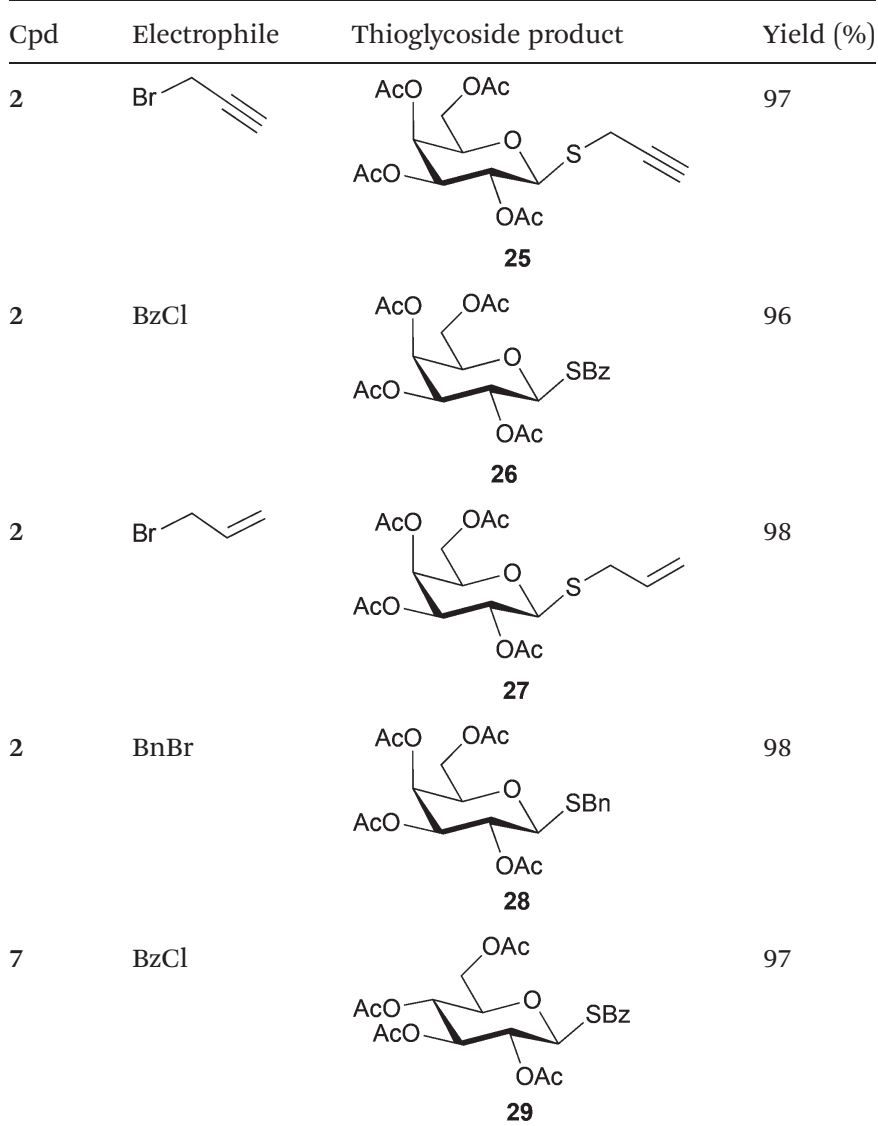

$\mathrm{BnBr}$

$\mathrm{BzCl}$

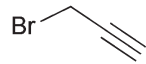

2

Table 3 One-pot de-silylation and glycosyl thiol alkylation with alkyl, acyl, and glycosyl halides ${ }^{a}$

11

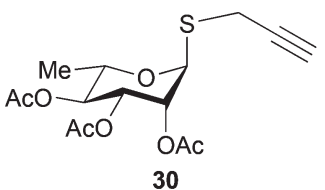

98

$1412^{32}$

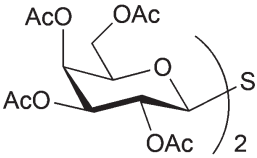

31

12

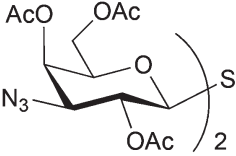

32

15 $13^{33}$

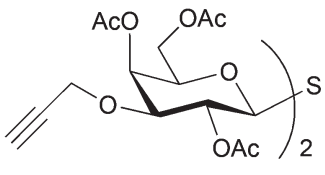

33

${ }^{a}$ STIPS glycoside (1 eq.), alkyl (1.3 eq.), acyl (1.3 eq.), or glycosyl halide (1 eq.), MeCN (26 mL mmol ${ }^{-1}$ STIPS glycoside), TBAF (1.2 eq., $1.0 \mathrm{M}$ in THF), $5 \mathrm{~min}$.

${ }^{a}$ STIPS glycoside (1 eq.), $\beta$-iodo-t-alanine ester (1.2 eq.), MeCN (26 mL $\mathrm{mmol}^{-1}$ STIPS glycoside), TBAF (1.2 eq., 1.0 M in THF), $5 \mathrm{~min}$. 
more, formation of glycosyl thiouronium intermediates commonly requires reaction at higher temperatures with thiourea and in many cases the glycosyl thiouronium intermediates show limited stability upon storage.

\section{Conclusions}

In summary, this report presents an efficient and convenient one-pot protocol for stereoselective synthesis of thioglycoside derivatives by room temperature and one-pot TBAF-mediated de-silylation and nucleophilic reactions of storage-stable TIPS thio-glycosides towards Michael acceptors, as well as alkyl, acyl, and glycosyl halides in high yields.

\section{Acknowledgements}

The authors thank The Swedish Research Council (grant no. 621-2009-5326) and the European Community's Seventh Framework Program (FP7-2007-2013) under grant agreement no. HEALTH-F2-2011-256986 (PANACREAS) for financial support. SM thanks The Swedish Institute for providing a postdoctoral scholarship.

\section{Notes and references}

1 B. Ernst and J. L. Magnani, Nat. Rev. Drug Discovery, 2009, 8, 661-677.

2 M. von Itzstein, Curr. Opin. Struct. Biol., 2008, 18, 558-566.

3 Z. J. Witczak and J. M. Culhane, Appl. Microbiol. Biotechnol., 2005, 69, 237-244.

4 K. Pachamuthu and R. R. Schmidt, Chem. Rev., 2006, 106, 160-187.

5 L. Szilágyi and O. Varela, Curr. Org. Chem., 2006, 10, 17451770.

6 Z. J. Witczak and D. Boryczewski, Bioorg. Med. Chem. Lett., 1998, 8, 3265-3268.

7 F. Schweizer and O. Hindsgaul, Curr. Opin. Chem. Biol., 1999, 3, 291-298.

8 H. Leffler and S. H. Barondes, J. Biol. Chem., 1986, 22, 10119-10126.

9 K. A. Stannard, P. M. Collins, K. Ito, E. M. Sullivan, S. A. Scott, E. Gabutero, I. Darren Grice, P. Low, U. J. Nilsson, H. Leffler, H. Blanchard and S. J. Ralph, Cancer Lett., 2010, 299, 95-110.

10 T. Delaine, I. Cumpstey, L. Ingrassia, M. Le Mercier, P. Okechukwu, H. Leffler, R. Kiss and U. J. Nilsson, J. Med. Chem., 2008, 51, 8109-8114.

11 A. C. MacKinnon, S. L. Farnworth, P. S. Hodkinson, N. C. Henderson, K. M. Atkinson, H. Leffler, U. J. Nilsson, C. Haslett, S. J. Forbes and T. Sethi, J. Immunol., 2008, 180, 2650-2658.

12 A. C. Mackinnon, M. A. Gibbons, S. L. Farnworth, H. Leffler, U. J. Nilsson, T. Delaine, A. J. Simpson,
S. J. Forbes, N. Hirani, J. Gauldie and T. Sethi, Am. J. Respir. Crit. Care Med., 2012, 185, 537-546.

13 V. Volarevic, M. Milovanovic, B. Ljujic, N. Pejnovic, N. Arsenijevic, U. Nilsson, H. Leffler and M. L. Lukic, Hepatology, 2012, 55, 1954-1964.

14 T. Saksida, I. Nikolic, M. Vujicic, U. J. Nilsson, H. Leffler, M. L. Lukic, I. Stojanovic and S. Stosic-Grujicic, J. Cell Physiol., 2013, 228, 1568-1576.

15 M. Kohn, J. M. Benito, C. Ortiz Mellet, T. K. Lindhorst and J. M. Garcia Fernandez, ChemBioChem, 2004, 5, 771-777.

16 M. Gingras, Y. M. Chabre, M. Roy and R. Roy, Chem. Soc. Rev., 2013, 42, 4823-4841.

17 G. M. Watt and G. J. Boons, Carbohydr. Res., 2004, 339, 181-193.

18 N. Floyd, B. Vijayakrishnan, J. R. Koeppe and B. G. Davis, Angew. Chem., Int. Ed., 2009, 48, 7798-7802.

19 U. J. Nilsson, E. J.-L. Fournier, E. J. Fryz and O. Hindsgaul, Comb. Chem. High Throughput Screening, 1999, 2, 335-352.

20 U. J. Nilsson, E. J.-L. Fournier and O. Hindsgaul, Bioorg. Med. Chem., 1998, 6, 1563-1575.

21 Z. J. Witczak, Phosphorus, Sulfur Silicon Relat. Elem., 2013, 188, 413-417.

22 D. Ellis, S. E. Norman and H. Osborn, Tetrahedron, 2008, 64, 2832-2854.

23 V. E. Manzano, M. L. Uhrig and O. Varela, J. Org. Chem., 2008, 73, 7224-7235.

24 G. J. L. Bernardes, D. P. Gamblin and B. G. Davis, Angew. Chem., Int. Ed., 2006, 45, 4007-4011.

25 X. Zhu, R. T. Dere, J. Jiang, L. Zhang and X. Wang, J. Org. Chem., 2011, 76, 10187-10197.

26 E. I. Miranda, M. J. Díaz, I. Rosado and J. A. Soderquist, Tetrahedron Lett., 1994, 35, 3221-3224.

27 A. Rane, E. Miranda and J. Soderquist, Tetrahedron Lett., 1994, 35, 3225-3226.

28 J. J. Marugan, C. Manthey, B. Anaclerio, L. Lafrance, T. B. Lu, T. Markotan, K. A. Leonard, C. Crysler, S. Eisennagel, M. Dasgupta and B. Tomczuk, J. Med. Chem., 2005, 48, 926-934.

29 X. Billot, A. Chateauneuf, N. Chauret, D. Denis, G. Greig, M. C. Mathieu, K. M. Metters, D. M. Slipetz and R. N. Young, Bioorg. Med. Chem. Lett., 2003, 13, 1129-1132.

30 D. P. Galonić, W. A. van der Donk and D. Y. Gin, Chem. Eur. J., 2003, 9, 5997-6006.

31 Z. Zhang and G. Magnusson, Carbohydr. Res., 1996, 295, 41-55.

32 T. L. Lowary and O. Hindsgaul, Carbohydr. Res., 1994, 251, 33-67.

33 U. J. Nilsson, H. Leffler, B. Mukhopadhyay and V. K. Rajput, PCT Int. Appl., WO 2013110704 A1 20130801, 2013.

34 E. S. H. El Ashry, L. F. Awad, H. M. A. Hamid and A. I. Atta, J. Carbohydr. Chem., 2005, 24, 745-753.

35 P. Tiwari, G. Agnihotri and A. K. Misra, J. Carbohydr. Chem., 2005, 24, 723-732.

36 M. Van Scherpenzeel, E. E. Moret, L. Ballell, R. M. J. Liskamp, U. J. Nilsson, H. Leffler and R. J. Pieters, ChemBioChem, 2009, 10, 1724-1733. 